\title{
Pengaruh Audiovisual Menonton Film Kartun Terhadap Tingkat Kecemasan Saat Prosedur Injeksi Pada Anak Prasekolah
}

\author{
Lilis Fatmawati, Yuanita Syaiful, Diyah Ratnawati \\ Universitas Gresik, lilisfatmawati13@gmail.com
}

\begin{abstract}
Abstrak
Anak usia prasekolah menganggap sakit adalah sesuatu hal yang menakutkan. Anak mempunyai keterbatasan dalam mekanisme koping mengatasi krisis tersebut. Intervensi audiovisual menonton film kartun merupakan teknik distraksi untuk menurunkan kecemasan pada anak. Tujuan penelitian untuk menganalisis pengaruh audiovisual menonton film kartun terhadap tingkat kecemasan saat prosedur injeksi pada anak prasekolah. Penelitian ini Pre-experimental dengan jenis pretest and posttest one group design. Pengambilan data dengan mengunakan teknik purposive sampling pada 28 responden. Variabel independen audiovisual menonton film kartun, sedangkan variabel dependen tingkat kecemasan. Instrumen yang digunakan SOP dan skala kecemasan HAR-S. Uji statistik menggunakan uji Paired Sample T-Test, dengan signifikasi $p<0,05$. Hasil analisis statistik didapatkan nilai sig $(p=0.001, t=11,71)$ yang berarti ada pengaruh audiovisual menonton film kartun terhadap tingkat kecemasan saat prosedur injeksi pada anak prasekolah. Diharapkan intervensi audiovisual menonton film kartun dapat diterapkan sebagai salah satu intervensi keperawatan untuk menurunkan kecemasan saat prosedur injeksi pada anak prasekolah.
\end{abstract}

Kata kunci : Anak Prasekolah, Audiovisual, Kecemasan, Prosedur Injeksi

\begin{abstract}
Among preschoolers, illness is a scary thing. Children have limitations in coping mechanisms to overcome the crisis. Audiovisual intervention in watching cartoons is a distraction technique to reduce anxiety in children. The purpose of the study was to analyze the effect of audiovisual cartoon movie on anxiety levels during injection procedures in preschool children. The design of this study was using Pre-experimental pretest and posttest one group design. The research collecting the data using purposive sampling technique on 28 respondents. Independent variable audiovisual watching cartoons, while dependent variable is anxiety level. The instrument used is SOP and $H A R-S$ anxiety scale. Statistical tests using the Paired Sample T-Test, with significance $\mathrm{p}$ $<0.05$. From the results of the statistical analysis, the sig value was obtained $(p=0.001$, $\mathrm{t}=11.71$ ) which means an audiovisual intervention by on watching cartoons movie was effective to reduce anxiety levels during the injection procedure in preschool children. We suggest that audiovisual intervention by watching cartoons movie can be applied as one of the nursing interventions to reduce anxiety during injection procedures in preschool children.
\end{abstract}

Keywords: Anxiety, Audiovisual, Injection Procedure, Preschool Children

\section{PENDAHULUAN}

Anak-anak adalah suatu awal kehidupan untuk masa-masa berikutnya (Nursalam, 2013). Anak prasekolah (3-6 tahun) merupakan masa yang menyenangkan, dipengaruhi dengan segala macam hal yang baru. Anak prasekolah memiliki ketrampilan verbal dan perkembangan menjadi lebih baik untuk beradaptasi di berbagai situasi, tetapi penyakit dan 
hospitalisasi bisa menyebabkan stress. Tetapi kenyataaannya tidak semua anak mengalami masa-masa menyenangkan, anak juga mengalami sakit yang mengharuskan mereka dirawat di rumah sakit (Utami, 2014). Sakit dan hospitalisasi terjadi pada anak bisa mengakibatkan stress dan kecemasan disemua tingkat usia. Penyebab kecemasan dipengaruhi oleh banyak faktor, dari petugas rumah sakit (dokter, perawat, serta tenaga kesehatan lainnya), lingkungan baru, reaksi keluarga yang mendampingi anak selama perawatan (Nursalam, dkk, 2013). Seringkali mereka harus menjalani intervensi medis atau tindakan invasive yang dapat menimbulkan ketakutan pada anak seperti prosedur injeksi, pengambilan atau tes sampel darah, operasi, medikasi dan intervensi keperawatan lainnya.

WHO (2012) bahwa 3-10 \% anak dirawat di Amerika Serikat baik anak usia toddler, prasekolah ataupun anak usia sekolah, di Jerman sekitar 3 - 7\% anak toddler dan 5 - 10\% anak prasekolah yang menjalani hospitalisasi (Purwandari, 2013 dalam Carla, 2017). UNICEF jumlah anak usia prasekolah di 3 negara terbesar dunia mencapai 148 juta, 958 anak dengan insiden anak yang dirawat di rumah sakit 57 juta anak setiap tahunnya dimana $75 \%$ mengalami trauma berupa ketakutan dan kecemasan saat menjalani perawatan
(James, 2010 dalam Saputro H dan Intan Fazrin, 2017). Di Indonesia sendiri jumlah anak yang dirawat pada tahun 2014 sebanyak 15,26\% (Susenas, 2014). Anak usia prasekolah, anak usia sekolah merupakan usia rentan terhadap penyakit, sehingga banyak anak usia tersebut harus dirawat di rumah sakit, serta menyebabkan populasi anak yang dirawat di rumah sakit mengalami peningkatan sangat dramatis (Wong, 2009).

Miller (2002) kecemasan anak saat menjalani hospitalisasi berkisar $10 \%$ mengalami kecemasan ringan, itu berlanjut, sekitar 2\% mengalami kecemasan berat. Penelitian dilakukan untuk melihat respon hospitalisasi terjadi anak usia 3-12 tahun didapatkan bahwa $77 \%$ anak mengatakan nyeri serta takut saat dilakukan pengambilan darah, 63\% anak mengalami kekakuan otot, $63 \%$ anak menangis sampai berteriak (Burnsnader, 2014 dalam Carla, 2017). Diperkirakan 35 per 100 anak menjalani hospitalisasi $45 \%$ diantaranya mengalami kecemasan saat menjalani perawatan di Rumah Sakit (Depkes, 2010 dalam Widiatmoko, 2018).

Berdasarkan data dari Badan Pusat Statistik (BPS) Jawa Timur dapat dijelaskan bahwa anak usia prasekolah dari tahun ke tahun semakin meningkat, data tahun 2013 menunjukkan jumlah anak usia prasekolah yang ada di Jawa Timur 
2.485.218 dengan angka kesakitan 1.475.197, mengalami kecemasan saat menjalani perawatan akibat sakitnya sebanyak 85\% (Dinkes Propinsi Jawa Timur, 2014 dalam Saputro H dan Intan Fazrin, 2017). Data yang di Rumah Sakit Semen Gresik tahun 2017 terdapat 3043 anak yang dirawat, diantaranya 758 anak usia prasekolah. Pada bulan Januari - April 2018 terdapat 1173 anak yang dirawat, terdapat 262 anak usia prasekolah.

Data tingkat kecemasan anak yang diukur dengan menggunakan kuisioner Hamilton Rating Scala for Anxiety (HRSA) yang dilakukan pada tanggal 21 - 27 Mei 2018 di Rumah Sakit Semen Gresik terdapat 10 anak usia prasekolah (3-5 th) yang dirawat dan dilakukan tindakan pemberian injeksi, terdapat $3(30 \%)$ anak mengalami kecemasan sedang, 5 (50\%) mengalami kecemasan berat, sedangkan 2 (20\%) anak mengalami kecemasan ringan, dari data tersebut menunjukkan anak yang mengalami kecemasan berat di ruang anak rawat inap Rumah Sakit Semen Gresik masih cukup banyak. Selama ini perawat maupun tenaga kesehatan lainnya hanya menggunakan teknik komunikasi langsung (direct) berupa instruksi sederhana maupun modeling. Namun pemberian audiovisual terhadap tingkat kecemasan saat dilakukan prosedur pemberian injeksi pada anak prasekolah belum bisa dijelaskan.
Anak usia prasekolah menganggap sakit adalah sesuatu hal yang menakutkan, kehilangan lingkungan yang aman dan penuh kasih sayang, serta tidak menyenangkan (Supartini, 2014). Asuhan keperawatan pada anak biasanya memerlukan tindakan invasif seperti injeksi atau pemasangan infus, hal ini merupakan stresor kuat yang dapat membuat anak mengalami kecemasan. Perawat biasanya akan menjelaskan prosedur ini kepada orangtua dan melakukan komunikasi terapeutik kepada anak sebelum melakukan prosedur tersebut, kondisi ini juga membuat anak menjadi panik dan biasanya melakukan perlawanan atau menolak untuk dilakukan posedur pemasangan infus atau injeksi obat, yang biasanya akan memaksa petugas kesehatan untuk sedikit melakukan paksaan kepada anak yang mengakibatkan timbulnya trauma pada anak. Reaksi anak terhadap tindakan invasive ini ditunjukkan dengan agresi fisik dan verbal (Hockenberry, Wilson \& Winkelstein, 2008).

Oleh karena itu anak seringkali menunjukkan perilaku tidak kooperatif seperti sering menangis, marah-marah, tidak mau makan, rewel, susah tidur, mudah tersinggung, meminta pulang dan tidak mau berinteraksi dengan perawat dan seringkali menolak jika akan diberikan 
pengobatan. Kondisi cemas yang terjadi pada anak akan menghambat dan menyulitkan proses pengobatan yang berdampak terhadap penyembuhan pada anak sehingga memperpanjang masa rawat dan dapat beresiko terkena komplikasi dari infeksi nosokomial serta menimbulkan trauma pada anak. Untuk mengatasi memburuknya tingkat kecemasan pada anak, seorang perawat dalam memberikan intervensi kepada anak harus memperhatikan kebutuhan anak sesuai dengan pertumbuhan anaknya.

Beberapa tindakan yang pernah dilakukan untuk menurunkan tingkat kecemasan pada anak antara lain: bermain boneka, bermain clay, bermain puzzle, aktivitas mewarnai, terapi musik, juga tehnik komunikasi terapeutik, serta tehnik pengalihan perhatian (distraksi). Kombinasi antara distraksi pendengaran (audio) dan distraksi penglihatan (visual) disebut distraksi audiovisual, yang digunakan untuk mengalihkan perhatian pasien terhadap sesuatu yang membuatnya tidak nyaman, cemas atau takut dengan cara menampilkan tayangan favorit berupa gambar-gambar bergerak dan bersuara ataupun animasi dengan harapan pasien asik terhadap tontonannya sehingga mengabaikan rasa tidak nyaman dan menunjukkan respon penerimaan yang baik.
Audiovisual yang digemari oleh anakanak usia prasekolah adalah kartun atau gambar bergerak, merupakan media yang sangat menarik bagi anak-anak terutama anak usia prasekolah yang memiliki daya imajinasi tinggi. Anak juga dapat mengeksplorasi perasaan, emosi, dan daya ingat melalui audio visual, audio visual juga dapat membantu perawat dalam melaksanakan prosedur infus dan injeksi, memudahkan perawat dalam mendistraksi agar anak kooperatif dalam pelaksanaan prosedur terapi (Tamsuri, 2007). Cara yang dilakukan yaitu dengan memfokuskan perhatian pada suatu hal yang disukai oleh anak, misalnya menonton film kartun (Maharezi, 2014 dalam Hapsari 2016). Berdasarkan latar belakang di atas, maka peneliti tertarik melakukan penelitian tentang pengaruh audiovisual menonton film kartun terhadap tingkat kecemasan saat prosedur injeksi pada anak prasekolah.

\section{METODE}

Penelitian ini menggunakan desain praexperimental dengan rancang bangun onegrup pra-post test design. Penelitian dilaksanakan pada 5-28 Januari 2019. Populasinya adalah seluruh anak usia prasekolah yang masuk di Ruang Anak Rumah Sakit Semen Gresik. Pengambilan sampel menggunakan teknik purposive sampling, sebanyak 28 responden. 
Variabel independen (audiovisual menonton film kartun), Upin Ipin, Doraemon dan Frozen The Snow yang diputar dengan menggunakan tablet phone.

Variabel dependen (tingkat kecemasan). Intervensi menonton film kartun diberikan selama minimal 10 menit, sedangkan prosedur injeksi durante menonton film kartun. Alat ukur yang digunakan pada penelitian ini adalah kuesioner $H A R-S$ yang merupakan pengukuran kecemasan didasarkan pada munculnya simptom pada individu yang mengalami kecemasan. Prosedur penelitiannya yaitu peneliti akan melakukan pre test kepada responden pada hari kedua rawat inap saat diberikan prosedur injeksi. Kemudian kuesioner (tingkat kecemasan HAR-S) diisi oleh keluarga berdasarkan hasil observasi saat itu, pada hari yang sama saat jadwal pemberian injeksi selanjutya, peneliti akan memberikan intervensi audiovisual menonton film kartun, berupa salah satu film kartun anak Upin Ipin, Frozen the snow, Doraemon, sesuai kesediaan pasien. Pemberian intervensi film kartun tersebut diberikan minimal 10 menit. Sedangkan prosedur injeksi diberikan durante menonton film kartun. Dalam memberikan intervensi audiovisual film kartun perawat juga melibatkan keluarga dan teman perawat dalam satu ruang rawat inap tersebut, demikian juga dalam proses dokumentasi. Peneliti melakukan post test untuk pengambilan data tingkat kecemasan responden menggunakan ceklis kuesioner kecemasan skala $H A R-S$ yang diisikan oleh keluarga/orangtua responden.

Dalam penelitian ini menggunakan analisa univariat dan bivariat menggunakan uji Paired T-test untuk mengamati ada tidaknya perbedaan dari dua data yang merupakan sebuah sampel tetapi mengalami perlakuan yang berbeda.

Tabel 1. Tingkat Kecemasan Sebelum dan Sesudah Intervensi Audiovisual Menonton Film Kartun Saat Prosedur Injeksi Pada Anak Prasekolah di Ruang Anak Rumah Sakit Semen Gresik pada tanggal 5-28 Januari 2019

\begin{tabular}{lcccc}
\hline \multirow{2}{*}{$\begin{array}{c}\text { Tingkat } \\
\text { Kecemasan }\end{array}$} & \multicolumn{2}{c}{ Sebelum Interensi } & \multicolumn{2}{c}{ Sesudah Intervensi } \\
\cline { 2 - 5 } & Frekuensi & Persentase (\%) & Frekuensi & Persentase (\%) \\
\hline Tidak cemas & 2 & 7.1 & 23 & 82.1 \\
Ringan & 6 & 21.4 & 3 & 10.7 \\
Sedang & 2 & 7.1 & 1 & 3.6 \\
Berat & 17 & 60.7 & 1 & 3.6 \\
Panik & 1 & 3.6 & 0 & 0 \\
\hline \multicolumn{1}{c}{ Total } & $\mathbf{2 8}$ & $\mathbf{1 0 0 . 0}$ & $\mathbf{2 8}$ & $\mathbf{1 0 0 . 0}$ \\
\hline
\end{tabular}

Sumber: Data Primer 2019 
Tabel 2. Pengaruh Audiovisual Terhadap Tingkat Kecemasan Saat Prosedur Injeksi Pada Anak Prasekolah di Ruang Anak Rumah Sakit Semen Gresik pada tanggal 5-28 Januari 2019

\begin{tabular}{|c|c|c|c|c|}
\hline \multirow{3}{*}{ Tingkat Kecemasan } & \multicolumn{4}{|c|}{ Intervensi Audiovisual Menonton Film Kartun } \\
\hline & \multicolumn{2}{|c|}{ Sebelum intervensi } & \multicolumn{2}{|c|}{ Sesudah intervensi } \\
\hline & $\mathbf{F}$ & $\%$ & $\mathbf{F}$ & $\%$ \\
\hline Tidak cemas & 2 & 7.1 & 23 & 82.1 \\
\hline Ringan & 6 & 21.4 & 3 & 10.7 \\
\hline Sedang & 2 & 7.1 & 1 & 3.6 \\
\hline Berat & 17 & 60.7 & 1 & 3.6 \\
\hline Panik & 1 & 3.6 & 0 & 0.0 \\
\hline Total & 28 & 100.0 & 28 & 100.0 \\
\hline Mean & \multicolumn{2}{|l|}{28.67} & \multicolumn{2}{|c|}{11.75} \\
\hline Std.Deviation & \multicolumn{2}{|l|}{9.03} & \multicolumn{2}{|c|}{5.00} \\
\hline Paired Sample T-Test nilai sig (2-tailed) & $p=0.000$ & $t=11.61$ & & \\
\hline
\end{tabular}

Sumber: Data Primer 2019

\section{PEMBAHASAN}

1. Tingkat Kecemasan Sebelum Intervensi Audiovisual Menonton Film Kartun Saat Prosedur Injeksi Pada Anak Prasekolah

Berdasarkan tabel 1 menunjukkan bahwa hasil penelitian sebelum intervensi audiovisual menonton film kartun saat prosedur injeksi pada anak prasekolah sebagian besar mengalami kecemasan berat sebanyak 17 (60.7\%). Sama dengan penelitian sebelumnya mengenai pengaruh terapi audiovisual terhadap tingkat kecemasan anak usia prasekolah yang dilakukan pemasangan infus sebagian besar mengalami kecemasan berat $55.6 \%$ (Ganda, 2017).

Kondisi cemas yang terjadi pada anak yang menjalani hospitalisasi dan mendapatkan tindakan invasif harus mendapat perhatian khusus dan segera diatasi. Bagi anak usia prasekolah (3-6 tahun) menjalani hospitalisasi dan mengalami tindakan invasif merupakan suatu keadaan krisis disebabkan karena adanya perubahan status kesehatan, lingkungan, faktor keluarga, kebiasaan atau prosedur yang dapat menimbulkan nyeri dan kehilangan kemandirian pada anak (Wong, 2009). Lingkungan rumah sakit, petugas kesehatan dan alat-alat yang berada di rumah sakit yang baru dilihat oleh anak menyebabkan anak menjadi takut dan cemas. Penyebab stress dan kecemasan pada anak dipengaruhi oleh banyak faktor, diantaranya perilaku yang ditunjukkan petugas kesehatan (dokter, perawat dan tenaga kesehatan lainnya), pengalaman hospitalisasi anak, support system atau dukungan keluarga yang mendampingi selama perawatan. Faktorfaktor tersebut dapat menyebabkan anak 
menjadi semakin stress dan hal ini berpengaruh terhadap proses penyembuhan (Nursalam dkk., 2013).

Peneliti mengambil sampel usia 3-6 tahun atau rentang perkembangan anak usia prasekolah. Berdasarkan karakteristik responden didapatkan umur responden adalah anak usia 3-4 tahun sebanyak 46\%, usia 4,1-5 tahun 25\%, usia 5,1-6 tahun $29 \%$, dan usia 6 tahun 23\%. Pengumpulan data penelitian yang dilakukan anak yang berada pada usia 3 tahun memiliki tingkat kecemasan yang tinggi. Menurut Lau (2002) dalam Apriliawati (2011) anak usia infant, toodler, preschool lebih memungkinkan mengalami stress akibat perpisahan karena kemampuan kognitif anak yang masih terbatas untuk memahami hospitalisasi.

Beberapa penelitian menyatakan bahwa semakin muda usia anak, kecemasan hospitalisasi akan semakin tinggi (Mahat \& Scoloveno, 2003). Menurut Utami (2014), anak merupakan populasi yang sangat rentan terutama saat menghadapi situasi yang membuat stress. Hal ini dikarenakan kondisi koping yang digunakan oleh orang dewasa belum berkembang sempurna pada anak-anak. Anak usia prasekolah menerima keadaaan masuk rumah sakit dengan rasa ketakutan. Jika anak sangat ketakutan dapat menampilkan perilaku agresif, dari menggigit, menendang-nendang bahkan berlari ke luar ruangan.

Selain umur, jenis kelamin juga dapat mempengaruhi kecemasan dan stress pada anak, dimana anak perempuan prasekolah yang menjalani hospitalisasi memiliki tingkat kecemasan yang lebih tinggi dibandingkan laki-laki. Distribusi dalam penelitian ini didapatkan $57 \%$ responden adalah perempuan. Demikian juga dalam penelitian (Stubbe, 2008 dalam Apriliawati, 2011) menyebutkan bahwa anak perempuan yang menjalani hospitalisasi memiliki kecemasan yang lebih tinggi dibandingkan dengan anak laki-laki.

Pengalaman hopitalisasi pada anak akan mempengaruhi kecemasan yang dialami oleh anak. Sebagaimana yang dijelaskan oleh Tsai (2007) dalam Apriliawati (2011) anak yang memiliki pengalaman menjalani hospitalisasi memiliki kecemasan lebih rendah dibanding anak yang belum memiliki pengalaman hospitalisasi. Namun dalam penelitian ini didominasi oleh anak yang sebelumnya pernah dirawat di rumah sakit sebanyak 18 anak (64\%). Hal ini dimungkinkan terkait dengan tindakan atau prosedur medis yang pernah didapat sebelumnya mungkin menyebabkan trauma walaupun anak pernah dirawat tetapi memiliki pengalaman tidak menyenangkan sehingga anak tetap 
mengalami kecemasan. Hal ini sesuai dengan penelitian yang menyatakan bahwa pengalaman hospitalisasi tidak berpengaruh terhadap tingkat kecemasan anak (Stubbe, 2008 dalam Apriliawati, 2011).

Berdasarkan teori dan hasil penelitian yang didapat, terdapat keselarasan dimana terdapat beberapa faktor yang dapat mempengaruhi tingkat kecemasan pada anak. Pada anak usia prasekolah penyebab kecemasan berkaitan dengan umur, pengalaman dirawat sebelumnya, yang dapat menuyebabkan tinggi atau rendahnya tingkat kecemasannya. Tingkat kecemasan saat prosedur injeksi sebelum intervensi audovisual sebagian besar mengalami kecemasan berat 17 responden $(60.7 \%)$, dan didapatkan rata-rata skor tertinggi pada gejala menangis, merengek, berteriak dan memberontak. Hal ini selaras dengan teori Supartini (2014) dimana anak usia prasekolah menganggap sakit adalah sesuatu hal yang menakutkan, kehilangan lingkungan yang aman dan penuh kasih sayang, serta tidak menyenangkan. Anak menganggap tindakan dan prosedur rumah sakit menyebabkan rasa sakit dan luka di tubuhnya.

Ketakutan anak muncul karena anak menganggap tindakan dan prosedurnya mengancam intregitas tubuhnya. Oleh karena itu, menimbulkan reaksi agresif dengan marah, dan berontak. Demikian pula disebutkan oleh Stuart (2009) anak yang dirawat di rumah sakit dengan kecemasan yang tinggi memiliki kecenderungan menjadi hiperaktif dan tidak kooperatif terhadap petugas kesehatan serta menimbulkan gangguan psikologik berupa perubahan perilaku seperti gelisah, menangis, dan memberontak.

2. Tingkat Kecemasan Sesudah Intervensi Audiovisual Menonton Film Kartun Saat Prosedur Injeksi Pada Anak Prasekolah

Berdasarkan tabel 1 menunjukkan bahwa hasil penelitian sesudah dilakukan audiovisual menonton film kartun saat prosedur injeksi pada anak prasekolah, hampir seluruhnya tidak mengalami kecemasan yaitu sebanyak 23 (82.1\%). Penelitian ini sesuai dengan Wahyuningrum (2015) dalam pengaruh cerita melalui audiovisual terhadap tingkat kecemasan anak usia prasekolah yang mengalami hospitalisasi setelah dilakukan intervensi sebagian besar mengalami kecemasan dengan kategori ringan (59.1\%). Penelitian Patma (2017) dalam penelitiannya tingkat kecemasan setelah diberikan terapi audiovisual pada pasien yang dilakukan pemasangan infus, sebagian besar mengalami kecemasan ringan yaitu 6 responden (66.7\%). 
Demikian pula dalam penelitian ini setelah intervensi audiovisual menonton film kartun saat prosedur injeksi pada anak prasekolah, masih didapatkan nilai ratarata ketakutan pada skor tertinggi yaitu, takut diinjeksi dan takut pada orang asing/perawat. Hal ini selaras dengan teori yang dikemukakan Kozlowski dkk., (2013), salah satu kecemasan yang dirasakan oleh pasien anak ketika harus mendapatkan perawatan di rumah sakit adalah tindakan invasif, seperti pemberian obat injeksi yang dilakukan oleh tim kesehatan. Tindakan invasif pemberian obat injeksi, baik menyakitkan atau tidak merupakan suatu ancaman bagi anak usia prasekolah karena mereka menganggap tindakan invasif merupakan sumber kerusakan terhadap integritas tubuhnya. Mott (2005) lingkungan rumah sakit yang dianggap asing oleh anak akan meningkatkan kecemasan anak pada saat dirawat di rumah sakit (Apriliawati, 2011).

Kondisi cemas yang terjadi pada anak yang menjalani hospitalisasi dan mendapatkan tindakan invasif harus mendapat perhatian khusus dan segera diatasi (Wong, 2009). Intervensi audiovisual menonton film kartun adalah sebuah proses yang akan membentuk imajinasi pada anak, memberikan kesempatan pada anak untuk lebih menangkap informasi, edukasi dan hiburan serta dapat mengekspresikan perasaannya (Koller dan Goldman, 2012, dalam Patma, 2017).

Anak-anak menyukai unsur-unsur seperti gambar, warna, cerita pada film kartun animasi. Unsur-unsur seperti gambar, warna dan cerita dan emosi (senang, sedih, seru, bersemangat) yang terdapat pada film kartun merupakan unsur otak kanan dan suara yang timbul dari film tersebut merupakan unsur otak kiri. Unsur grafis pada sajian anak prasekolah adalah unsur yang paling penting karena pada anak prasekolah unsur lisan dan audio hanya mendapatkan perhatian sebesar $2 \%$ dan $98 \%$ sisanya diporsikan pada unsur visual statis (Evans dkk., 2008 dalam Wahyuningrum, 2015). Sehingga dengan menonton film kartun animasi seperti Upin Ipin, Doraemon ataupun Frozen the Snow, otak kanan dan otak kiri anak pada saat bersamaan digunakan dua-duanya secara seimbang dan anak fokus pada film kartun (Wahyuningrum, 2015).

Dengan memberikan sajian interaktif visual (gambar statis) dan video (gambar dinamis) maka konsentrasi anak terhadap audiovisual yang dilihat akan meningkat. Sehingga audiovisual menonton film kartun dapat memudahkan anak untuk mendapatkan pembelajaran dengan basis yang menyenangkan. Sehingga pemanfaatan audiovisual dapat membantu dan 
memudahkan perawat dalam mendistraksi agar anak kooperatif dalam pelaksanaan prosedur injeksi (Taufik, 2007).

\section{Pengaruh Audiovisual Terhadap \\ Tingkat Kecemasan Saat Prosedur \\ Injeksi Pada Anak Prasekolah}

Hasil uji analisa Paired $T$ Tes untuk mengetahui Pengaruh Audiovisual Menonton Film KartunTerhadap Tingkat Kecemasan Saat Prosedur Injeksi Pada Anak Prasekolah, pada penelitian ini didapatkan hasil sig (2-tailed) $p=0.000$, $p<0.05$ maka H0 ditolak dan H1 diterima yang berarti ada pengaruh audiovisual menonton film kartun terhadap tingkat kecemasan saat prosedur injeksi pada anak prasekolah di Ruang Anak Rumah Sakit Semen Gresik. Hasil penelitian ini sejalan pada penelitian Wahyuningrum (2015), bahwa pemberian cerita melalui audiovisual efektif dalam menurunkan tingkat kecemasan pada anak usia prasekolah yang mengalami hospitalisasi.

Berdasarkan tabel 3 tingkat kecemasan anak sesudah diberikan audiovisual menonton film kartun saat prosedur injeksi pada anak prasekolah hampir seluruhnya tidak mengalami kecemasan, yaitu sebanyak 23 responden $(82,1 \%)$. Tingkat kecemasan yang berbeda pada tiap anak disebabkan pula karena respon setiap manusia terhadap stressor memang berbeda. Hal ini sesuai dengan model kognitif kecemasan yang menyebutkan bahwa respon yang berbeda pada tiap individu antara lain dipengaruhi oleh adanya kelemahan dalam berbagai proses informasi (Blackburn, 1990, dalam Juanita, 2017. Namun masih didapatkan 1 responden mengalami kecemasan berat sesudah intervensi audiovisual menonton film kartun, meskipun responden kooperatif saat diberikan intervensi audiovisual menonton film kartun, dan masih menunjukkan rasa takut saat akan diinjeksi, takut pada perawat, gelisah, tegang, menangis, berteriak dan memberontak hingga menunjukkan muka merah dan penurunan nafsu makan. Hal ini dimungkinkan karena pasien mempunyai riwayat sudah pernah dirawat dua kali sebelumnya, sehingga pernah mempunyai pengalaman yang masih menjadi sumber kecemasan baginya, diantaranya pengalaman mendapatkan prosedur injeksi serta pemasangan infus.

Apabila anak mengalami kecemasan tinggi saat dilakukan tindakan invasif, kemungkinan besar tindakan yang dilakukan menjadi tidak maksimal dan tidak jarang harus mengulangi beberapa kali sehingga akan menghambat proses penyembuhan anak. Kondisi ini mempersulit perawat dalam melakukan tindakan keperawatan (Supartini, 2014). Perlu adanya upaya dalam menurunkan tingkat 
kecemasan terutama saat prosedur injeksi, diantaranya dengan distraksi audiovisual (Tamsuri, 2007).

Koller dan Goldman (2012) dalam studinya menyatakan bahwa pemberian cerita melalui audiovisual guna menurunkan kecemasan termasuk teknik distraksi kecemasan dengan teknik audiovisual. Perhatian anak yang terfokus kepada cerita audiovisual yang disimaknya mendistraksikan atau mengalihkan persepsi kecemasan anak dalam korteks serebral. Dengan intervensi audiovisual menonton film kartun akan memberikan rangsangan distraksi berupa visual, auditory dan tactile. Perasaan aman dan nyaman yang dirasakan anak akan merangsang tubuh untuk mengeluarkan hormon endorphine.

Melalui pemberian audiosivisual menonton film kartun yang diberikan oleh perawat diharapkan dapat membantu anak dalam mengatasi permasalahan dengan meminta mereka ikut terlibat tentang kegiatan atau tindakan injeksi yang diberikan oleh petugas sehingga dapat membantu membangun pikiran dan kemungkinan dapat menyelesaikan masalah yang berhubungan dengan penyakit, perpisahan selama dirawat, kecacatan dan keterasingan. Hal ini terlihat pada saat penelitian anak menjadi fokus dengan tayangan audiovisual menonton film kartun dibandingkan prosedur injeksi, walaupun anak masih tetap harus di dampingi dan tetap dekat dengan orangtuanya. Hasil uji analisis statistik didapatkan adanya perbedaan tingkat kecemasan pada pre test dan post test pada anak yang diberikan audiovisual menonton film kartun saat prosedur injeksi. Ini berarti bahwa ada pengaruh audiovisual menonton film kartun dalam menurunkan tingkat kecemasan saat prosedur injeksi pada anak prasekolah, baik secara subyekstif maupun obyektif. Hal tersebut sesuai dengan teori bahwa salah satu cara yang dapat dilakukan untuk pengendalian kecemasan adalah tehnik distraksi audiovisual untuk mengalihkan perhatian anak (Tamsuri, 2007, dalam Agustina 2015). Perhatian anak menjadi teralihkan pada film kartun yang disukai anak, yang menyebabkan anak tidak lagi memikirkan prosedur injeksi, anak menjadi rileks dan nyaman sehingga menurun kecemasannya.

\section{KESIMPULAN}

Sebelum diberi intervensi sebagian responden memiliki kecemasan berat, sedangkan sesudah diberi intervensi hampir seluruh responden tidak mengalami kecemasan. Sehingga Ada pengaruh pemberian audiovisual menonton film kartun terhadap penurunan tingkat kecemasan saat prosedur injeksi pada anak prasekolah. 


\section{DAFTAR PUSTAKA}

Agustina, H, (2015). Pengaruh Distraksi Audiovisual Terhadap Respon Penerimaan Injeksi Intravena Pada Anak Prasekolah di RSD Kalisat Jember. Skripsi PSIK FIK Universitas Muhammadiyah Jember Indonesia.

Apriliawati, A. (2011). Pengaruh Biblioterapi Terhadap Tingkat Kecemasan Anak Usia Sekolah Yang Menjalani Hospitalisasi di Rumah Sakit Islam Jakarta. Tesis Pogram Magister Ilmu Keperawatan Anak Universitas Indonesia Depok.

Ardiyanto, Kurniawan. (2011). Hubungan Dukungan Sosial Terhadap Kecemasan Keluarga Pasien di Ruang HND RSUP Dr. Kariadi Semarang. Skripsi PSIK FIK Universitas Muhammadiyah Semarang.

Arikunto, Suharsimi (2010). Prosedur Penelitian: Suatu Pendekatan Praktis, Jakarta: Rineka Cipta.

Asmadi. (2008). Teknik Prosedural Konsep \& Aplikasi Kebutuhan Dasar Klien. Jakarta: Salemba Medika.

Bossert. (1994) Factor influencing the coping of hospitalization school- age children. Journal of Pediatric Nursing. 9 (5): 299-306

Coyne, I. (2006). Children's experiences of hospitalization. Journal of Child Health, 10 (4): 326-336

Dimyati dan Mudjiono (2006). Belajar dan Media Pembelajaran. Jakarta: Rineka Cipta, h .78

Fosson, Abe., Martin, Judi. \& Haley, John. (2010). Anxiety Among Hospitalized Latency-Age Children. Journal of Developmental \& Behavioral Pediatric, 11(6), 28-339

Hanum, SA. (2015). Pengaruh Biblioterapi Terhadap Kecemasan Anak Usia Sekolah yang di Rawat Inap di RSUD Dr. Pirngadi Medan. Skripsi
Fakultas Keperawatan Universitas Sumatera Utara Medan Indonesia.

Hapsari, AY. (2016). Pengaruh Distraksi Video film Kartun Terhadap Kecemasan Anak Usia 6-8 Tahun Selama Tindakan Dental di RS Tk IV 04.07.02 Slamet Riyadi Surakarta. Publikasi Ilmiah Program Studi Pendidikan Dokter Gigi FK Gigi Universitas Muhammadiyah Surakarta.

Hartini, Sri. (2014). Pengaruh Biblioterapi Dengan Buku Cerita Bergambar Terhadap Tingkat Kecemasan Pada Anak Prasekolah Saat Pemasangan Infus di RS Telogorejo Semarang. Skripsi PSIK STIKES Telogorejo Semarang.

Journal/index.php/ilmukeperawatan/ari cle/view/290/314

Hawari, D. (2008). Menajemen Stres Cemas Dan Depresi. Fakultas Kedokteran Universitas Indonesia: Jakarta.

Hidayat, Aziz Aimul.(2008), Pengantar Ilmu Keperawatan. Jakarta : Salemba Medika.

Hockenberry, MarilynJ.,\& Wilson, David (2011). Wong's Clinical Manual of Pediatric Nursing $7^{\text {th }}$ Ed.USA: Mosby Elseiver

Jainar, Rahmatika. (2016). Perbandingan Efektifitas Menonton Film Dengan Terapi Bermain Terhadap Penurunan Kecemasan Anak Umur 6-8 Tahun Selama Perawatan Gigi. Skripsi S1 Pendidikan Dokter Gigi Fakultas Kedokteran Gigi Universitas Muhammadiyah Surakarta.

Juanita, Farida. (2017). Teknik Distraksi Audiovisual Menurunkan Tingkat Kecemasan Anak Usia Sekolah Yang Menjalani Sirkumsisi. Jurnal Ners. Vol 2. No 2 (2007). http://dx.doi.org/10.20473/jn.v2i2.4962.

Kautsar, F., Dayal, G \& Fuad, A. (2015). Uji Validitas dan Reliabilitas Hamilton 
Anxiety Rating Scale Terhadap Kecemasan dan Produktivitas Pekerja Visual Inspection PT. Widatra Bhakti. Seminar Nasional Teknologi 2015 Institut Teknologi Nasional Malang ISSN: $\quad 2407-\quad 7534$. email:kautsar_fuad@yahoo.co.id.dayal_ gustopo@yahoo.co.id,fuadachmadi@g mail.com. Diakses 6 Agustud 2018.

Kirkpatrick, T., \& Tobias, K. (2013). Pediatric age specific: self learning module. $\quad$ Dari http://hr.uclahealth.org/workfiles/AgeS pecificSLM-Peds.pdf. Diperoleh pada tanggal 28 Mei.

Koller dan Goldman, 2012. Pediatric Psychosocial Oncology: Textbook for Multidisciplinary Care, USA: Springer

Kusumadewi, Sri. (2008). Aplikasi Fuzzy Total Integral Pada Hamilton Anxiety Rating Scale (HAR-S). Jurusan Teknik Informatika, Universitas Islam Indonesia, Yogyakarta Jl. Kaliurang K, 14,5 Yogyakarta. Seminar Nasional Aplikasi Teknologi Informasi 2008 (SNATI 2008) Yogyakarta, 21 Juni 2008 ISSN: 1907-5022. E-mail: cicie@fti.uii.ac.id. Diakses 10 Agustus 2018

Kurniawati, Rizka. (2016). Pengaruh Terapi Bermain Mewarnai terhadap tingkat kecemasan akibat Hospitalisasi pada Anak Usia Prasekolah di Bangsal Cempaka RSUD WATES. Skripsi, PSIK Jendral A. Yani, Yogyakarta.

Kozlowski, Lori J, \& Monitto, C. L. (2013). Pain in hospitalized children. Pediatrics for Parents. http://search.proquest.com/d ocview/ diakses pada tanggal 5 Maret 2018.

Kristina, (2017). Pengaruh Kegiatan Mewarnai Pola Mandala Terhadap Tingkat Kecemasan Mahasiswa Akademi Keperawatan Dirgahayu Samarinda. Nurse Line Journal Vol. 2 No. 1 Mei 2017 p-ISSN 2540-7937 e-
ISSN 2541-464X. e-mail: tina.kenny@yahoo.co.i

Kurniawan, Ardiyanto. (2011). Hubungan dukungan sosial terhadap kecemasan keluarga pasien di ruang HND RSUP Dr. Kariadi Semarang. Skripsi PSIK Fakultas Kesehatan Universitas Muhammadiyah Semarang.

Kyle, Terry dan Susan Carman. (2016). Buku Ajar Keperawatan Pediatri. Jakarta: EGC.

Latifah, ON. (2014). Hubungan Komunikasi Terapeutik Perawat dengan Tingkat Kecemasan Anak Usia Prasekolah Di RSUD Panembahan Senopati Bantul. Skripsi PSIK Sekolah Tinggi Ilmu Kesehatan Jendral Achmad Yani, Yogyakarta.

Lemos, I. C. S., Silva, L. G. D., Delmondes, G. D. A., Brasil, A. X., Santos, P. L. F., Gomes, E., Silva, K. V. L. G. D., Oliveira, D. D., Oliveira, J. D. D., Fernandes, G. P., \& Kerntopf, M. R. (2016). Therapeutic Play Use in Children under the Venipucture: A Strategy for Pain Reduction. American Journal of Nursing Research, 4(1), 1-5.

Lumiu, S.E., Tuda, J.S.B., \& Ponidjan, T. (2013), Hubungan Dukungan Keluarga dengan Tingkat Kecemasan Akibat Hospitalisasi pada Anak di Usia Pra Sekolah di Irina E Blu RSUD Prof. Dr. R. D Kandau Manad, Ejurnal Keperawatan (e-kep), Vol 1 no $1,5$. Email: stella.lumiu@yahoo.com

Miller. (2002). Clinical Pathology Edisi 2. Jakarta: EGC.

Munadi, Y., 2011, Media Pembelajaran Sebuah Pendekatan Baru, Jakarta: Gaung Persada Press.

Muscari, E. M. (2013). Keperawatan Pediatrik. Jakarta: EGC

Nasbar, Carla. (2017). Pengaruh Penerapan Atraumatic Care Medial Play Terhadap Respon Kecemasan 
Anak Usia Prasekolah yang Hospitalisasi di Ruang Rawat Inap Anak RSUD Dr. M. Zein Painan Tahun 2017. Skripsi PSIK Fakultas Keperawatan Universitas Andalas Padang Sumatera Barat.

Notoatmodjo, S. (2012). Metodologi Penelitian Kesehatan, Peneltian Ilmiah. Jakarta: Rineka Cipta.

Nursalam, Susilaningrum, R \& Utami, S. (2013). Asuhan Keperawatan Bayi dan Anak (Untuk Perawat dan Bidan). Jakarta: Salemba Medika.

Nursalam. (2016). Metodologi Penelitian Ilmu Keperawatan: Pendekatan Praktis. Edisi 3 Salemba Medika.

Patma GN, Mohammad Nofiyanto 2017 Pengaruh Terapi Audio Visual Terhadap Penurunan Tingkat Kecemasan Pada Anak Preschool Yang dilakukan Tindakan Pemasangan Infus di UGD RSUD Wates. Skripsi S1 Keperawatan Program Studi Keperawatan STIKES Jenderal Achmad Yani Yogyakarta. Email: gandasuprobo27@gmail.com

Pillitteri, A., 2010, Maternal \& Child Health Nursing: Care of the Childbearing \& Childrearing Family, New York: Lippincott Williams \& Wilkins.

Potts, Nicki L., \& Mandleco, Barbara L. (2012). Pediatric Nursing: Caring for Children and Their Families. USA: Delmar.

Potter, A., \& Perry, A. G. (2010). Buku ajar fundamental keperawatan: Konsep, proses, dan praktik (edisi 4). Jakarta: EGC.

PSIK FIK UNGRES. (2018). Pedoman Penyusunan Proposal dan Skripsi. Gresik

Rahayuningrum, Madyastuti, L \& Mafulah. (2015). Hubungan Peran Orangtua dengan Kecemasan
Hositalisasi pada anak Prasekolah (Correlation of Parent Roles and Hospitalization Anxiety to The Preschoole Age Children Patients). Journal of News Community. Volume 06, Nomor 02. Hal. 158-165.

Ramdaniati, S., Hermaningsih, S. \& Muryati. (2016). Comparison Study of Art Therapy in Reducing Anxiety on Pre-School Children Who Experience Hospitalization. Open Journal of Nursing, 6, 46-52.

Rusdi AE. (2015) Pengaruh Tehnik Distraksi Menonton Film Kartun Untuk Menurunkan Stress Hospitalisasi Pada Anak Prasekolah di RSUD Tugurejo. ejournal.stikestelogorejo.ac.id/index.ph p/ilmukeperawatan/article/viewFile/569 1568

Saputro, Heri \& Fazrin, Intan. (2017). Penurunan Tingkat Kecemasan Anak Akibat Hospitalisasi dengan Penerapan Terapi Bermain. Jurnal Konseling Indonesia. Vol.3 No. 1. Hal. 9-12

Sarfika Rika, Nova Yanti, Ruspita Winda (2015). Pengaruh Teknik Distraksi Menonton Kartun Animasi Terhadap Skala Nyeri Anak Usia Prasekolah Saat Pemasangan Infus Di Instalasi Rawat Inap Anak RSUP DR.M.Djamil Padang. Ners Jurnal Keperawatan, 11 (1). 3240. Email: rikasarfika@gmail.com

Soetjiningsih. (2012). Tumbuh Kembang Anak, Jakarta: EGC.

Supartini. (2014). Buku Ajar Konsep Dasar Keperawatan Anak. Jakarta: EGC.

Sureskiarti E. (2017). Perbedaan Kecemasan Anak Usia Prasekolah Pada Tindakan Injeksi Dengan Diterapkan Dan Tanpa Diterapkan Pemakaian Rompi Bergambar Di Ruang Melati Rsud Abdul Wahab Sjahranie Samarinda. Program Studi Ilmu Keperawatan STIKES Muhammadiyah: Samarinda. Jurnal Ilmiah Manuntung. 
Vol. 3 No. 1. Vol. 3 No. 1 (2017). http://jurnal.akfarsam.ac.id/index.php/jl m_akfarsam/article/view/98

Sutrisno, Widodo, G.G, Susanto, H., (2017). Kecemasan Anak Usia Sekolah Sebelum dan Sesudah Mendapatkan Informasi Saat Pemberian Obat Injeksi di RSUD Ambarawa. Journal Ilmu Kesehatan 2 (2) 2017, 99-106. http:// ejournal.stikesaisyah.ac.id/index.php/jik a/

Stuart, Gail W. (2016). Keperawatan Kesehatan Jiwa. Singapore: Elsevier.

Stubbe, D. A. (2008). A focus on reducing anxiety in children hospitalized for cancer and diverse pediatric medical disease through a self-enganging art therapy. Dissertation. The Faculty of the School of Professional Psychology. Chestnut Hill Colleege.

Tamsuri. (2007). Konsep dan Penatalaksanaan Nyeri. Jakarta: EGC

Townsend, Mary C. (2009), Buku Saku Diagnosa Keperawatan pada Keperawatan Keperawatan Psikiatri Edisi 6. Jakarta: EGC.
Tsai, C. (2007), 'The effect of animal assisted therapy on children's stress during hospitalization'. Doctoral Disttertasi of Phylosopy. University of Marylan, School of Nursing.

Utami, Yuli. (2014). DampakHospitalisasi Terhadap Perkembangan Anak. Jurnal Ilmiah Widya Volume 2, Nomor 2. Hal. 9-20.

Wahyuningrum I, (2015). Pengaruh Cerita Melalui Audiovisual TerhadapTingkat kecemasan Anak Usia Prasekolah Yang Mengalami Hospitalisasi Di RSU PKU Muhmmadiyah Bantul. Skripi S1 Program Studi Ilmu Keperawatan STIKES 'Aisyiyah Yogyakarta. Email: fhya091193@gmail.com

Wong, D. L. et.al. (2009). Buku Ajar Keperawatan Pediatrik, vol 1. Jakarta: EGC

Yongblut, J.M. (2010). “Alternate Child Care, History of Hospitalization, And Preschool Child Behavior". Nurs Res, 48 (1), 29-34. 